Research Article

$\mathrm{J}$ Exp Clin Med

2021; 38(S1): 71-73

doi: 10.52142 /omujecm.38.si.gastro.11

\title{
Can asymptomatic Crohn's Disease be diagnosed in patients with iron deficiency anemia by CT-enterography?
}

\author{
Ufuk AVCIOĞLU ${ }^{1, *}$, Ayşegül İDİL SOYLU²
}

${ }^{1}$ Department of Gastroenterology, Faculty of Medicine, Ondokuz Mayıs University, Samsun, Turkey

${ }^{2}$ Department of Radiology, Faculty of Medicine, Ondokuz Mayıs University, Samsun, Turkey

\begin{abstract}
\begin{tabular}{ccccc}
\hline Received: 07.09 .2020 & $\bullet$ & Accepted/Published Online: 06.11 .2020 & $\bullet$ & Final Version: 18.03 .2021 \\
\hline
\end{tabular}
Abstract

It is difficult to diagnose Crohn's disease in the asymptomatic period. The aim of this study is to evaluate the diagnostic utility of CT enterorrhaphy (CTE) in the diagnosis of asymptomatic Crohn's disease (CD) with small intestine involment in patients with iron deficiency anemia (IDA). 250 patients who underwent CTE examination between 2017 and 2018 were retrospectively scanned. Forty-five patients who had endoscopic examinations and diagnosed with IDA were included in the study. While one or more pathological findings to explain IDA were observed in 31 (68\%) patients with endoscopic examinations, findings that could be explained as CD sequelae were observed in four (8.8\%) patients. No lesions were observed by CTE in $10(22.2 \%)$ patients. Diagnosis is difficult in mild forms of Crohn's disease or in periods of remission. In this period, CTE can contribute to the diagnosis as it can also show extraluminal findings.
\end{abstract}

Keywords: crohn's disease, iron deficiency anemia, CT enterography

\section{Introduction}

Crohn's disease (CD) is an inflammatory disease of the digestive system that may affect any segment of the gastrointestinal tract from mouth to anus with focal, asymmetrical and transmural involvement. There are no pathognomonic clinical, serological, endoscopic and microscopic findings in $\mathrm{CD}$. The main findings of $\mathrm{CD}$ are the presence of intestinal inflammation that does not persist endoscopically and radiologically, and granulomas (but not necessarily) in the biopsy material. Anemia is defined by the World Health Organization as the level of hemoglobin for adults is less than $13 \mathrm{~g} / \mathrm{dl}$ for men and $12 \mathrm{~g} / \mathrm{dl}$ for women (Beutler and Waalen, 2006). Anemia is a global public health problem affecting both developing and developed countries at all ages (Cappellini and Motta, 2015). IDA is the most common type of anemia. Gastrointestinal losses are the most common cause of IDA in adult men and postmenopausal women (Hardwick and Armstrong, 1997). The frequency of IDA in this patient group ranges from 2 to $5 \%$ (Looker et al., 1997). In this study, our aim is to evaluate the diagnostic utility of CT enterography (CTE) in the diagnosis of asymptomatic CD with small intestine involvement in patients with IDA.

\section{Materials and methods}

Two hundred fifty patients who underwent CTE examination in the radiology department of our hospital between 2017 and
2018 were retrospectively scanned. Patients who were previously diagnosed with $\mathrm{CD}$, those with a history of abdominal surgery and those without endoscopic examinations were excluded from the study. $\mathrm{Hb}, \mathrm{Htc}, \mathrm{MCV}, \mathrm{MCHC}$, ferritin, Neutrophil, sedimentation and CRP parameters of 81 patients who were examined with the diagnosis of IDA were evaluated. Forty-five patients diagnosed with IDA and whose endoscopic examinations were available were included in the study.

\section{Results}

There was a pathology to explain IDA with endoscopic examinations in $31(68 \%)$ patients. $10(22.2 \%)$ patients did not have any lesions in CTE while four $(8.8 \%)$ patients had findings that could be explained as $\mathrm{CD}$ sequelae. These findings were as follows: Strictures and adhesions in the mesentery of the left upper quadrant and at the level of cecum, appendix and distal ileum, incomplete rotation in the intestines in one patient; diffuse symmetrical edematous wall thickness in prepyloric antrum in one patient; diffuse symmetrical thickening of the terminal ileum wall in one patient; diffuse symmetrical thickening and minimal enhancement in terminal ileum in one patient. The demographic characteristics, laboratory findings and CTE findings of the patients are shown in Table 1. 
Table 1. Demographic characteristics, laboratory findings and CTE findings of patients with CD sequelae findings

\begin{tabular}{|l|l|c|c|c|c|c|c|c|l|}
\hline No & Age & Gender & $\begin{array}{c}\mathrm{Hb} \\
\mathrm{g} / \mathrm{dL}\end{array}$ & $\begin{array}{c}\text { Hct } \\
\%\end{array}$ & $\begin{array}{c}\text { Ferritin } \\
\mathrm{ng} / \mathrm{mL}\end{array}$ & $\begin{array}{c}\mathrm{ESR} \\
\mathrm{mm} / \mathrm{h}\end{array}$ & $\begin{array}{c}\mathrm{CRP} \\
\mathrm{mg} / \mathrm{dL}\end{array}$ & $\begin{array}{c}\text { Neutrophil } \\
\text { x109/L (SI) }\end{array}$ & \multicolumn{1}{c|}{$\begin{array}{c}\text { CTE } \\
\text { Findings }\end{array}$} \\
\hline $\mathbf{1}$ & 48 & $\mathrm{M}$ & 11.6 & 36.5 & 22.5 & 12 & 0.26 & 4.26 & $\begin{array}{l}\text { Strictures and adhesions } \\
\text { in the mesentery of the left upper } \\
\text { quadrant and at the level of } \\
\text { cecum, appendix and distal } \\
\text { ileum, incomplete rotation in the } \\
\text { intestines }\end{array}$ \\
\hline $\mathbf{2}$ & 77 & $\mathrm{M}$ & 11.5 & 35.2 & 17.5 & 18 & 0.44 & 2.44 & $\begin{array}{l}\text { Diffuse symmetrical edematous } \\
\text { wall thickness in prepiloric } \\
\text { antrum }\end{array}$ \\
\hline $\mathbf{3}$ & 22 & $\mathrm{M}$ & 11.6 & 33.9 & 10 & 33.8 & 0.3 & 3.60 & $\begin{array}{l}\text { Diffuse symmetrical thickening } \\
\text { of the terminal ileum wall }\end{array}$ \\
\hline $\mathbf{4}$ & 38 & $\mathrm{~F}$ & 10.0 & 31.9 & 6.08 & 39 & 0.33 & 5.77 & $\begin{array}{l}\text { Diffuse symmetrical thickening } \\
\text { and minimal enhancement in } \\
\text { terminal ileum }\end{array}$ \\
\hline
\end{tabular}

Hb: Hemoglobin; Hct: Hematocrit; ESR: Erithrocyte sedimentation rate, CRP: C-reactive protein

\section{Discussion}

Endoscopic and radiological techniques are used to differentiate small intestine pathologies. The small intestines are not radiologically well-visualized due to their localization, length and tightly placed locations on each other, nor do they allow for a complete and optimal endoscopic exploration. Due to the technical difficulties of endoscopic methods in examining small intestine pathologies, high cost of examination and difficulties in reaching the examination, radiological examinations such as $\mathrm{CT}$ and MRI are taking more place in clinical practice day by day. With multidetector CT devices developed in recent years, images with a thin section thickness of less than 1 millimeter are obtained during a single breath hold. Multiplanar reformatted images created with this method allow for a more detailed evaluation and characterization of small intestine pathologies and play an important role in revealing extraluminal complications and extraenteric anomalies (Bodily et al., 2006; Macari et al., 2007; Maglinte et al., 2006). In CTE method, in addition to the routine abdominal CT examination performed after intravenous contrast agent injection, small intestine distension is provided with an appropriate amount of neutral contrast agent given orally before the examination to allow optimal evaluation of the lumen and wall (Booya et al., 2006). The main current indications for CTE are suspected gastrointestinal bleeding, CD and small intestine neoplasms. In cases where adequate bowel distension can be achieved, wall thickness of 3 $\mathrm{mm}$ and above is defined as "increase in wall thickness" (Macari et al., 2007). The contrast pattern observed after intravenous contrast agent injection, the length of the involvement, the degree of thickening, whether the thickening is symmetrical, the localization of the lesion in small intestine (proximal or distal), the depth of involvement in the intestinal wall (mucosal, submucosal or serosal), mesentery and vascular pathologies can be evaluated with CT enterography (Berther et al., 2008).

Despite the common view that there is involvement in the form of 'skip areas' in CD, the inflammatory and spreading pattern in the bowels is completely individual (Bruining and Loftus, 2006). The form of inflammation in CD can be in the form of superficial lesions, as well as fibrous structures that penetrate the intestinal wall, mesenteric inflammatory masses, or fistulas accompanied by abscesses that surround the intestines. Serological studies are becoming more specific for $\mathrm{CD}$, but yet, they do not have sufficient positive predictive value to confirm the disease (Griffiths., 2013). The diagnosis of CD is made by the history, physical examination, laboratory tests and advanced diagnostic tests (endoscopy, biopsy, crosssectional imaging) with differentiation from other inflammatory enteropathies. The course of the disease is variable. While some patients have a continuous, active and progressive disease course, approximately 20 percent of patients experience long-term remission after the first attack (Solberg et al., 2007). The diagnostic efficacy of CTE for CD during active disease is over 90\% (Siddiki et al., 2009). Luminal pathology may not be seen in endoscopic examinations performed after the period of active disease in CD. CTE, which can detect sequelae due to fibrosis and inflammatory changes, especially in the ulcers descending below the mucosa, may contribute to the diagnosis. CD most commonly involves the terminal ileum and cecum (Satsangi et al., 2006). It is noteworthy that in our study, 3 of 4 patients with pathology in CTE had sequelae changes in this region that could be considered significant in terms of $\mathrm{CD}$, whereas there was no evidence of inflammation in the terminal ileum mucosa evaluated endoscopically. Although there was no evidence of mucosal inflammation in the prepyloric antrum region in endoscopy of one patient, findings that could be interpreted as sequel changes for $\mathrm{CD}$ were observed. However, since this region is also a risky region for peptic ulcer disease, it would be more appropriate to interpret these changes in favor of peptic ulcer sequelae. The negative aspects of CTE in terms of its contribution to the diagnosis of CD are that it is a radiationbased examination with necessity of optimizing the shooting technique, has indirect and nonspecific findings and does not allow histopathological sampling. However, even in 
symptomatic patients in CD, the tests that are used for diagnosis are insufficient in approximately $10 \%$ of the patients (Siddiki et al., 2009). In the remission periods and mild forms of CD, which is generally asymptomatic, the advantage of CTE to show extraluminal findings and sequelae changes may provide additional findings. Larger studies involving more patients are needed in this regard.

\section{Conflict of interest}

All authors declare no conflict of interest regarding this manuscript.

\section{Acknowledgments}

No competing financial interests exist.

\section{References}

1. Berther, R., Patak, M. A., Eckhardt, B., Erturk, S. M., Zollikofer, C. L., 2008. Comparison of neutral oral contrast versus positive oral contrast medium in abdominal multidetector CT. European Radiology. 18(9), 1902-1909.

2. Beutler, E., Waalen, J., 2006. The definition of anemia: what is the lower limit of normal of the blood hemoglobin concentration? Blood. 107 (5), 1747-1750.

3. Bodily, K. D., Fletcher, J. G., Solem, C. A., Johnson, C. D., Fidler, J. L., Barlow, J. M., Bruesewitz, M. R., McCollough, C. H., Sandborn, W. J., Loftus, E. V., Jr, Harmsen, W. S., Crownhart, B. S., 2006. Crohn Disease: mural attenuation and thickness at contrast-enhanced CT Enterography--correlation with endoscopic and histologic findings of inflammation. Radiology. 238 (2), 505516.

4. Booya, F., Fletcher, J. G., Huprich, J. E., Barlow, J. M., Johnson, C. D., Fidler, J. L., Solem, C. A., Sandborn, W. J., Loftus, E. V., Jr, Harmsen, W. S., 2006. Active Crohn disease: CT findings and interobserver agreement for enteric phase CT enterography. Radiology. 241 (3), 787-795.

5. Bruining, D. H., Loftus, E. V., 2006. Evolving diagnostic strategies for inflammatory bowel disease. Current gastroenterology reports, 8(6), 478-485.
6. Cappellini, M. D., Motta, I., 2015. Anemia in Clinical PracticeDefinition and Classification: Does Hemoglobin Change with Aging? Seminars in hematology. 52(4), 261-269.

7. Griffiths, A. M., 2013. Challenging question: can we diagnose Crohn's disease without histology? Digestive diseases (Basel, Switzerland). 31(2), 202-206.

8. Hardwick, R. H., Armstrong, C. P., 1997. Synchronous upper and lower gastrointestinal endoscopy is an effective method of investigating iron-deficiency anaemia. The British journal of surgery. 84 (12), 1725-1728.

9. Looker, A. C., Dallman, P. R., Carroll, M. D., Gunter, E. W., Johnson, C. L., 1997. Prevalence of iron deficiency in the United States. JAMA. 277 (12), 973-976.

10. Macari, M., Megibow, A. J., Balthazar, E. J., 2007. A pattern approach to the abnormal small bowel: observations at MDCT and CT enterography. AJR. American journal of roentgenology. 188(5), 1344-1355.

11. Maglinte, D. D., Sandrasegaran, K., Tann, M., 2006. Advances in alimentary tract imaging. World journal of gastroenterology. 12(20), 3139-3145.

12. Satsangi, J., Silverberg, M. S., Vermeire, S., Colombel, J. F., 2006. The Montreal classification of inflammatory bowel disease: controversies, consensus, and implications. Gut. 55(6), 749-753.

13. Siddiki, H. A., Fidler, J. L., Fletcher, J. G., Burton, S. S., Huprich, J. E., Hough, D. M., Johnson, C. D., Bruining, D. H., Loftus, E. V., Jr, Sandborn, W. J., Pardi, D. S., Mandrekar, J. N., 2009. Prospective comparison of state-of-the-art MR enterography and CT enterography in small-bowel Crohn's disease. AJR. American journal of roentgenology. 193(1), 113-121.

14. Solberg, I. C., Vatn, M. H., Høie, O., Stray, N., Sauar, J., Jahnsen, J., Moum, B., Lygren, I., IBSEN Study Group, 2007. Clinical course in Crohn's disease: results of a Norwegian populationbased ten-year follow-up study. Clinical gastroenterology and hepatology: the official clinical practice journal of the American Gastroenterological Association. 5(12), 1430-1438. 